\title{
DIGITAL MARKETING PERFORMANCE EVALUATION METHODS
}

\author{
Elina Gaitniece ${ }^{1}$
}

\begin{abstract}
The share of digital marketing from total marketing spending is increasing fast year by year. Still the majority of companies admit that they are missing clear methods on how to evaluate (positive/negative) effects obtained using digital marketing. As this field of digital marketing is relatively new, there are no firm and widely recognized measurement methods resulting in marketing specialists being confused by an overwhelming amount and variety of different digital marketing metrics and large amounts of data. Therefore, the aim of this paper is to list the existing methods which could help marketers to evaluate their digital marketing campaign effectiveness and to discuss these methods' effectiveness with experts. To achieve this aim, the author defined the following objectives for the paper: 1) to explore which digital marketing campaign effectiveness evaluation methods can be found in realized scientific research so far; 2) to assess the strengths and weaknesses of each method by conducting expert interviews; 3 ) to determine the practical application opportunities for each identified method; and 4) to draw conclusions and make recommendations for the practical usage of the studied methods. Research methods used were secondary data analysis and expert interviews. The secondary data analysis contained reviews of scientific research results in the field mentioned above. The expert interviews covered in-depth interviews with the main stakeholders - leading online retailers in the Baltics and digital marketing experts. The results show that the conversion evaluation method is most frequently used in theory and in practice as it can be best connected with direct business goals to increase sales. It also highlights that each method has some benefits to be used in specific situations, with specific aims.
\end{abstract}

JEL Classification Numbers: M31, M39; DOI: http://dx.doi.org/10.12955/cbup.v6.1145

Keywords: Digital marketing, campaign effectiveness, evaluation methods, e-marketing metrics

\section{Introduction}

The share of digital marketing from total marketing spending is increasing fast year by year. Still the majority of companies admit that they are missing clear methods on how to evaluate effects obtained using digital marketing (Leeflang et al., 2014). As this field of digital marketing is relatively new there are no firm and widely recognized measurement methods and marketing specialists are confused by the overwhelming amount and variety of different digital marketing metrics and large amounts of data (Stewart, 2009; Seggiea et al., 2007). Therefore, the aim of this paper is to list the existing broad methods which could help marketers to evaluate their digital marketing campaign effectiveness, and to discuss these methods with experts. To achieve this aim, the author defined the following objectives for the paper: 1) to explore which digital marketing campaign effectiveness evaluation methods can be found in realized scientific research so far; 2) to assess the strengths and weaknesses of each method by conducting expert interviews; 3 ) to draw conclusions and make recommendations for the practical usage of the studied methods.

\section{Review of existing digital marketing evaluation methods}

Marketing effectiveness assessment is a management process that determines which metrics will be used to measure a company's set marketing goals and evaluates the achieved results in comparison to previously set goals (Rust et al., 2004; Stewart, 2009; Strauss \& Frost, 2014). The objectives may relate to different market and company performance areas - clients (eg. customer satisfaction), competitors (eg. relative increase in market share), and financial performance (eg. profit). Correctly set targets are measurable with a clear measurement method and defined criteria (Belch \& Belch, 2015). There are a lot of different marketing metrics available, but there is a lack of a standardized marketing process that would clearly and precisely link marketing investments with company results. Neither is there a metric that would clearly allow for marketing metrics to be audited, make objective comparisons with competitors, make objective future forecasts, or link different levels of data (Stewart, 2009; Seggiea et al., 2007, Frösén et al., 2016, Leeflang et al., 2014).

In particular, digital marketing efficiency focuses on the electronic environment, it seeks to discover meaningful models and trends in available data and to understand the effectiveness of the techniques used. The ability to evaluate the effectiveness of applied techniques immediately or within a short period of time is one of the specific advantages of digital marketing, since virtually any activity is numerically measurable in the electronic environment. The challenge is to be able to meaningfully analyze the enormous amount of data in order to improve the consumer's online experience and increase the efficiency of digital marketing. Data analysis provides a deeper understanding of consumer behavior

\footnotetext{
${ }^{1}$ Faculty of Business, Management and Economics, University of Latvia, elina.gaitniece@gmail.com
} 
and allows you to quickly adapt tactics to achieve better results, allowing you to make informed decisions based on data analysis (Kumar, 2015; Laudon \& Traver, 2016; Davenport, 2013).

The first methods of evaluating digital marketing emerged in the 1990s and have been developing rapidly. The amount of data available has also risen sharply. According to Becker (2014), the company today generates the same amount of data each day as the whole period from the beginnings of civilization till the year 2003. There are many different estimates made by business experts and professional market analysts, but it's clear that data has already been produced unprecedented quantities and that its increase will continue to grow. This, in turn, allows for unprecedented opportunities for using this large quantity of data for the benefit of the public, and at the same time opens the door to the illegal and unethical use of private data by individuals. For an enterprise that is trying to attract customers with new technologies and to obtain data with new methods of collecting and analyzing information, it must be clear which metrics help to compare the results achieved with the goals set. The company's goals determine the metrics to use, unfortunately, in practice, the opposite often happens (Charlesworth, 2014). Farris et al (2010) have made an extensive list of marketing metrics. The report includes both traditional marketing metrics such as market share, sales team outcomes, discounts, reach and profit, and digital marketing metrics. VanHoose (2011) has evaluated banner marketing performance indicators. Ramos and Cota (2014) describe the search engine marketing metrics and emphasizes the importance of matching both digital and traditional marketing activities with a proper performance evaluation by analyzing pay per click (PPC) and other metrics. Surma (2011) describes the development of general business intelligence technologies and techniques. Fulgoni and Lipsman (2014) assess how the marketing of various digital media platforms affects the outcome of the integrated campaign and emphasizes that the best result of a campaign can be achieved only by integrating different platforms of traditional and digital media and by carefully evaluating the impact of all platform metrics on the overall result. Venkatesans (2015) focuses on tools that measure and predict customer loyalty. Kelly (2013) for her part, gives an overview of how to assess the impact of social media on achieving different goals - such as brand awareness, brand reputation management, guiding, customer service improvement, and lead generation by offering metrics to be used for analysis. Bhandari (2012) recommends the introduction of a social media GRP metric comparable to the TV Gross Rating Points (GRP), which would measure the significant impact of social networks on a purchasing decision cycle. Kumar, et al. (2016) has already carried out a specific study to quantify the extent to which the content generated by the company in social media influences the average purchase volume (basket) of a consumer and the purchase of supplementary products. Wiesel et al (2011) concluded that customer-initiated contacts have, in comparison with companyinitiated contacts, yielded much better returns in the traditional environment. It should be noted that the econometric measurements of the impact assessment of the electronic environment have only just begun, but they are expected to be well developed (Winer \& Neslin, 2014).

Almost every author who focuses on analyzing digital marketing metrics has its own way of grouping and analyzing them, and a uniformed methodology for measuring digital marketing effectiveness does not exist. However, the analysis of the literature above makes it possible to distinguish between six main directions (general goals and metrics used to measure their achievement) in the evaluation of the effectiveness of digital marketing. Those directions are briefly described below and further named "methods":

\section{Methods}

1) Conversion evaluation - this method focuses on questions on how many consumers have done activity targeted to them (it might be purchase, it might be submitting info, etc.) by digital marketing tools. For a conversion evaluation the following metrics are used - the number of clicks and percentage how often the "buy" or "where to buy" button is pressed, the impact of paid and natural search engine marketing on conversion, how which inflow channel was working in a conversion, and the number of purchases (Davenport, 2013; Charlesworth, 2014).

2) Evaluating the content of the website in the context of consumer behavior - factors evaluated are such as: - which element of the content was most relevant to the target audience, how visitors went through the website, which "calls to action" have yielded the highest conversion results, which website layout provides a higher conversion, therefore metrics such as how many visitors came to the website, from which resources (websites, search engines) these visitors came from, how long time they spend on the 
website, how many pages they viewed, whether they used mobile devices, what they did, when and where, why they left the website, etc. are used (Fulgoni et al., 2017).

3) Brand visibility, activity assessment - measures a company's/brand's activity in creating digital content. In this case, metrics such as - quantity, frequency and recency of elements such as bad news, social platform news, responses, comments, news articles, video and audio material placement, unique visitors, number of pages, impressions, number of searches, search engines rating, number of followers, number of registrations, subscription, and sentiment are used (Kelly, 2013; Strauss \& Frost, 2014; Chaney, 2009).

4) Interaction assessment in social media - measures consumer engagement in communication about and with a company's / the brand-based content. Indicators here are receiving various forms of response from the target audience. In this case, we measure metrics such as - quantity, frequency and recency of elements such as registration, consumer activity on social networks (favorites / likes / ratings), usage of links, downloads, subscriptions, fans, followers and friends, number of shares, reviews, page time spent; profile creation; user generated content; sentiment analysis, number of content views; number of applications for widgets, number of bookmarks and topic uses; number of shares, user-created content (Kumar et al., 2016; Hanna et al., 2011).

5) Evaluation of financial results - measures the results of digital marketing campaigns, expressed as financial values. In this case, metrics such as - costs and future prospects - for elements like brand visibility in communication, consumer value for the brand, the value of earned media, search engine evaluations, and leads conversion rates are measured (Spiller \& Tuten, 2015; Bendle et al., 2015).

6) Evaluation of individual phases of the buyer's decision cycles and search for interconnections. The digital marketing metrics such as reach, frequency, quest size, visibility are used for a trigger phase (when consumer identifies the problem and a need is created). The digital marketing metrics such as clicks, number of visits, duration of visits, bounce rates are used for the information search phase; while in the phase of active evaluation, digital marketing metrics such as user questions, subscriptions, and comments are used. At the stage of purchase, digital marketing metrics such as the number and percentage of conversions, the number and percentage of search engine conversions are used. But for post by evaluation phase, digital marketing metrics such as number of registrations, user reviews and ratings are applied (Lumb, 2104; Fulgoni \& Lipsman, 2014).

\section{Methodology used}

Qualitative interviews were done with chosen experts - digital marketing communication specialists who have been conducted evaluations of digital marketing campaigns at an international level over several years. Questions were developed based on comprehensive literature review findings. A questionnaire was pretested in person with two digital marketing practitioners before the interview process started. Pretest interviews were 60 minutes long, the verbal probing technique was used due to its appropriateness, efficiency, and effectiveness. After pretest interviews the questionaire was revised. A convenience sample of five individuals from the researcher's personal networks were chosen for final interviews. The participants were holding the following positions - three digital marketing managers in three different countries in an international company, one e-commerce manager, one digital marketing analyst from a regional management team of an international company. One-hour long interviews were conducted with experts via Skype. Interviews took place during the period of October to December 2017 to understand better which digital marketing evaluation methods are used in practice and how experts evaluate the before listed methods. Due to confidentiality reasons, the names of the interviewed experts are not provided. It is acknowledged that a relatively small number of specialists were interviewed and hence this is a limitation for our study.

\section{Results and discussion}

During the interviews the experts gave their opinion about existing methods available in the literature and described the theoretical part of this article. They assessed their strengths and weaknesses and gave their opinion about real-life applicability. According to the interviewees, the conversion evaluation method is most frequently used between companies and marketing specialists. It is most linked with company goals and most linked with sales results which can be best impacted by a growing conversion. According to experts, currently the biggest challenge is to optimize marketing investments between different digital communication channels to maximize conversion. Still, specialists agree that focusing 
only on conversion is very much a short-term approach and does not pay the needed attention to a company's long term goals to increase brand awareness and to the grow pipeline of consumers considering a purchase in the future.

The Second model, the evaluation of the content of a website in the context of consumer behavior was recognized by experts as an important and good approach for improving SEO (search engine optimization) results by improving webpage content, building external links, improving consumer experience in webpage, but used alone would only give too narrow attention to "owned media".

Brand visibility, the activity assessment method is recognized as needed to be "always on" to keep the brand's image on a right track, to keep it visible and recognized. But also, this method can't be used as the only evaluation of digital marketing activity as it is mainly focusing on too broad factors and it can't be directly linked with company's short term financial goals.

The Fourth method mostly focuses on consumer activities in social networks - experts evaluate this method as very important for companies who focus their marketing activities on creating consumer generated content, mostly used by small, new companies/brands and as one element from a total range of activities for bigger companies who include user generated content as part of their marketing strategy. Still, according to experts this method is too narrow to be used as the only way to evaluate the effectiveness of digital marketing.

The fifth method which focus on finances is the method that the experts recognize for which most companies aim for, but frequently are faced with obstacles as there are limitations to measuring the future impact of today's activities financially and to attribute investments versus results properly. As a consequence, measured ROI (return on investment) might lead to wrong conclusions about campaign effectiveness if the wider context of a campaign's impact is not taken into account and properly monetized.

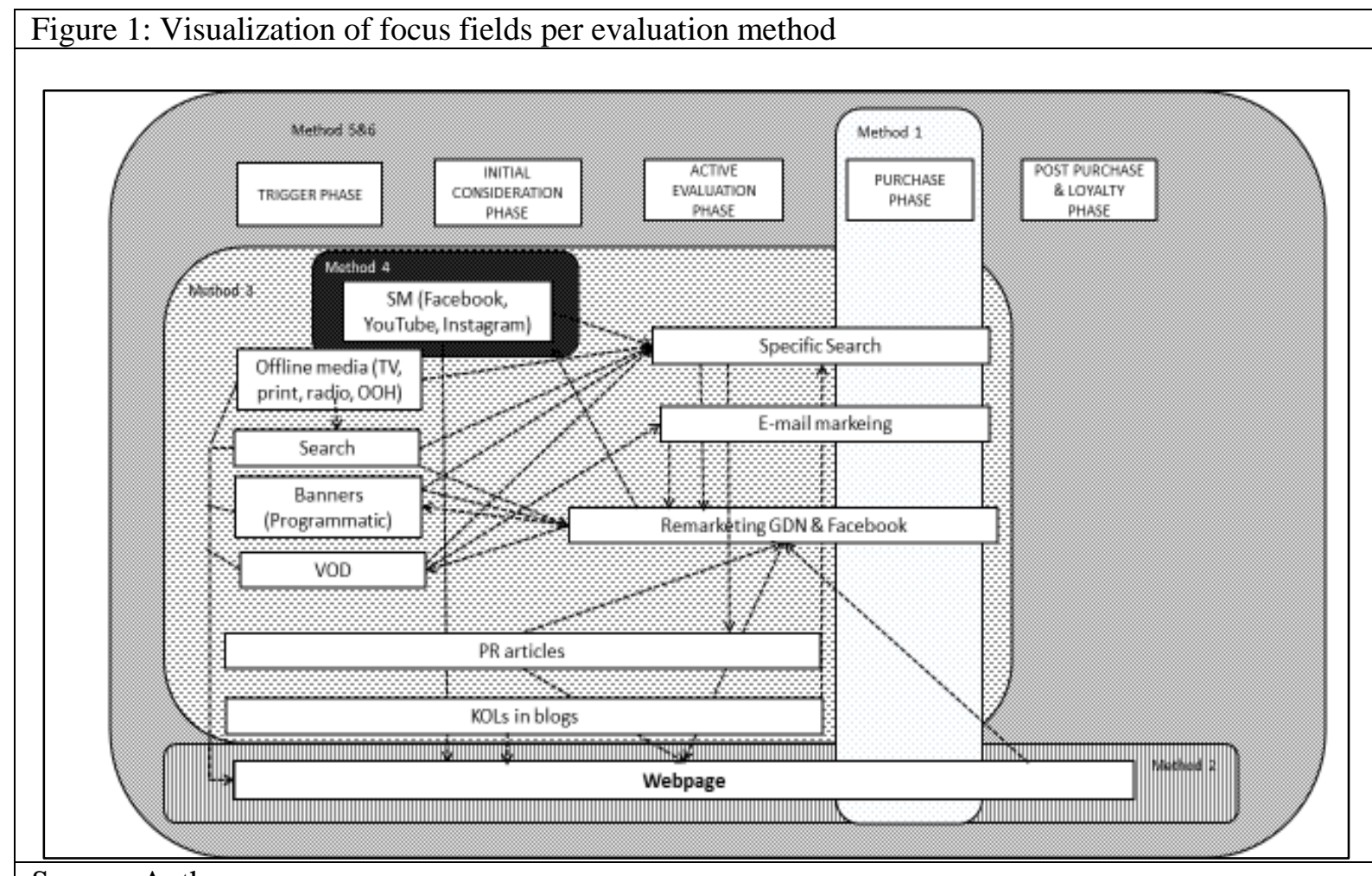

Source: Author

All experts had a quite similar opinion about the method nr. 6 - evaluation of individual phases of the buyer's decision cycles - provides most comprehensive look on companies' activities in digital field and not only, it allows to evaluate marketing activities from integrative perspective - taking into account also offline marketing activities and their impact to different consumer decision journey cycles. According to the interviewees, the primary benefit of the 5-stage model is that it requires the marketer to consider each decision-making phase when preparing marketing tactics. The seller has to consider how to approach the consumer in each particular phase and to develop communication tools for all of 
them if needed. So, even if a consumer takes shortcuts - which frequently happens in the case of lowcost products and frequent purchasing - there are still tools (communication) considered for touchpoints left (phases which consumers do not skip) to maximize the possible influence in each particular stage. If marketing tactics are well prepared and specific for each of the five phases - then the customer still may be affected during the purchasing moment by sales personnel or specially designed online or offline promotion in POS. Another strength of the model is its attention to the post-purchase evaluation phase which is important due to increasing electronic word of mouth communication across specific communication platforms.

Last to mention is the provided ability to analyze the market from this five-phase perspective. Market research tools now allow to segment the market and to recognize consumers who belong to a particular decision-making stage for some product or service. So, a company might decide to put the majority of their efforts to target consumers who are at the particular stage, and internet-based communication tools allow to prepare well-targeted communication campaigns for this specific audience. As interviewees admit, the main weakness of the model is its linear or step-by-step structure, because not all customers follow this particular structure and often some stages are skipped. Also, often in high-involvement purchases, customers go back to previous steps. However, even taking into account the above mentioned weaknesses, the five stage customer decision-making model is very well approbated in practice and frequently used as a backbone for marketing strategies.

\section{Conclusion}

Theoretical research followed by expert interviews allows following conclusions and recommendations. The buying process starts long before the actual purchase and lasts long after it, and this aspect has to be taken into account when analyzing digital marketing effectiveness. Taking that into account - experts evaluated six methods for which were the most comprehensive in the evaluation of digital marketing results. Still it was also mentioned that the usage of these methods requires a well established structure to monitor the wide range of digital marketing metrics and a well educated marketing staff which is able to recognize in which consumer decision phase is the respective target consumer. As a consequence, this method is advised to be used for "digitally mature" companies with big sizable digital marketing teams that have solid market experience. There are cases when a company focuses only on short term sales results and does their sales only in e-commerce sites - then the conversion evaluation method should be used according to expert opinion. For small start-up companies who aim to sell their products through peer recommendation networks, the best method to measure their digital marketing effectiveness would be the interaction assessment method. All experts agreed that the final decision on which method to use for a digital marketing effectiveness assessment should be done carefully, analyzing the market in which a company operates, it's strategic and tactic goals, it's resources and marketing team's 'digital maturity" level.

\section{References}

Becker, M. (2014). The consumer data revolution: The reshaping of industry competition and new perspective on privacy. Journal of direct data and digital marketing practice, 15(3), 2013-218.

Belch, G. E., \& Belch, M. A. (2015). Advertising and Promotion an Integrated Marketing Communications Perspective (10th ed.). New York: McGraw-Hill Education.

Bendle, N., Farris, P., Pfeifer, P., \& Reibstein, D. (2015). Metrics that Matter - to Marketing Managers. ResearchGate. Bhandari, R., Gordon, J., \& Umblijs, A. (2012, July 2). Getting beyond the buzz: Is your social media working? Financial Times.

Chaffey, D. (2011). E-business \& E-commerce: strategy, Implementation and Practice (5th ed.). Harlow: Pearson.

Chaney, P. (2009). The Digital Handshake : Seven Proven Strategies to Grow Your Business Using Social Media. Wiley.

Charlesworth, A. (2014). Digital Marketing: A Practical Approach (2nd ed.). Abingdon: Routledge.

Davenport, T. H. (2013). Enterprise Analytics Optimize Performance, Process, and Decisions Through Big Data. New Jersey: Pearson Education.

Edelman, D. C. (2010). Branding in the. Harvard Business Review.

Farris, P. W., Bendle, N. T., Pfeifer, P. E., \& Reibstein, D. J. (2010). Marketing Metrics: the Definitive Guide to Measuring Marketing Performance (2nd ed.). New Jersey: Pearson Education.

Frösén, J., Luoma, J., Jaakkola, M., Tikkanen, H., \& Aspara, J. (2016). What Counts Versus What Can Be Counted: The Complex Interplay of Market Orientation and Marketing Performance Measurement. Journal of Marketing, 80(3), 60-78. 
Fulgoni, G. M., Petit, R., \& Lipsman, A. (2017). Measuring the Effectiveness of Branded Content across Television and Digital Platforms: How to Align with Traditional Marketing Metrics While Capturing What Makes Branded Content Unique. Journal of Advertising Research, 57(4), 362-367.

Fulgoni, G., \& Lipsman, A. (2014). Numbers, Please: Digital Game Changers: How Social Media Will Help Usher in the Era of. Journal of Advertising Research, 54(1).

Hanna, R., Rohm, A., \& Crittenden, V. L. (2011). We're all connected: The power of the social media ecosystem. Business Horizons, 54(3), 265-273.

Iyengar, R., Han, S., \& Gupta, S. (2009). Do Friends Influence Purchases in a Social Network. Harvard Business School Marketing Unit Working Paper, 123(9).

Kaufman, I., \& Horton, C. (2015). Digital Marketing: Intergating Strategy and Tactics with Values (1st ed.). Routledge. Kelly, N. (2013). How to Measure Social Media A Step-by-Step Guide to Developing and Assessing Social Media ROI. Indianapolis: QUE.

Kotler, P., \& Armstrong, G. (2014). Principles of Marketing (14th ed.). Pearson Prentice Hall.

Kumar. (2015). Evolution of Marketing as a Discipline: What Has Happened and What to Look Out For. Journal of Marketing, 79(1), 1-9.

Kumar, A., Bezawada, R., Rishika, R., Janakiraman, R., \& Kannan, P. (2016). From Social to Sale: The Effects of Firm Generated Content in Social Media on Customer Behavior. Journal of Marketing, 80(1), 7-25.

Laudon, K. C., \& Traver, C. G. (2016). E-commerce 2016. Business. Technology. Society. (12th ed.). Pearson.

Leeflang, P. S., Verhoef, P. C., Dahlström, P., \& Freundt, T. (2014). Challenges and solutions for marketing in a digital era. European Management Journal, 32(1), 1-12.

Lumb, C. (2104). The Customer Decision Process and User Interaction in E-commerce. The University of Leeds .

Ramos, A., \& Cota, S. (2014). Search engine marketing. New York: McGraw-Hill.

Rust, R. T., Ambler, T., Carpenter, G. S., Kumar, V., \& Srivastava, R. K. (2004). Measuring Marketing Productivity: Current Knowledge and Future Directions. Journal of Marketing, 68(4), 76-89.

Seggiea, S. H., Cavusgilb, E., \& Phelan, S. E. (2007). Measurement of return on marketing investment: A conceptual framework and the future of marketing metrics. Industrial Marketing Management, 36(6), 834-841.

Spiller, L., \& Tuten, T. (2015). Integrating Metrics Across the Marketing Curriculum: The Digital and Social Media Opportunity. Journal of Marketing Education , 37(2), 114-126.

Stewart, D. W. (2009). Marketing accountability: Linking marketing actions to financial results. Journal of Business, 62(6), 636-43.

Strauss, J., \& Frost, R. (2014). e-marketing (7th ed.). Pearson.

Surma, J. (2011). Business Inteligence: Making Decisions through data analytics. New York: Business Expert press.

VanHoose, D. D. (2011). E-Commerce Economics (2nd ed.). Abingdon: Routledge.

Venkatesan, R., Farris, P., \& Wilcox, R. T. (2015). Cutting-Edge Marketing Analytics. New Jersey: Pearson.

Wiesel, T., Pauwels, K., \& Arts, J. (2011). Practice Prize Paper--Marketing's Profit Impact: Quantifying Online and Off-line Funnel Progression. Marketing Science, 30(4), 604-611.

Winer, R. S., \& Neslin, S. A. (2014). The History of Marketing Science. Singapore: World Scientific Publishing Co. 